\title{
Yield-reliability analysis and operating rules for run-of-river abstractions for typical rural water supply: Siloam Village case study
}

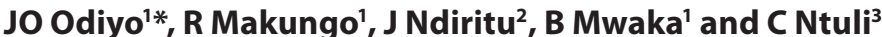 \\ 'Department of Hydrology and Water Resources, University of Venda, P/Bag X5050, Thohoyandou 0950 \\ ${ }^{2}$ School of Civil and Environmental Engineering, University of the Witwatersrand, P/Bag X3, Wits 2050 \\ ${ }^{3}$ Department of Water Affairs, P/Bag X313, Pretoria 0001
}

\begin{abstract}
The study focused on yield-reliability analysis and operating rules for optimum scheduling of run-of-river (ROR) abstractions for typical rural water supply schemes using Siloam Village, Limpopo Province, South Africa, as a case study. Efficient operation of water supply systems requires operating rules as decision support tools. System operation methods have hardly been developed or applied to water supply to rural communities that depend on ROR abstractions. Simulated runoff was used to derive unregulated river yield at different levels of assurance of supply (LAS) for Nzhelele River at Siloam Village using 1-day flow duration curves. Yield-reliability analysis results were used to derive operating rules. The results show that Nzhelele River can meet domestic and low-flow requirements at 50-80\% (1:2-1:5) LAS. The low-flow and domestic water requirements can be partially met at $90 \%(1: 10)$ LAS. The generic operating rules for ROR abstractions were consequently derived from the procedure used in developing operating rules for Nzhelele River. This enables generation of operating rules for ROR abstractions in any typical rural water supply system.
\end{abstract}

Keywords: operating rules, run-of-river abstractions, rural water supply, Siloam Village, yield-reliability analysis

\section{INTRODUCTION}

Though the National Water Act (No. 36 of 1998) of South Africa (SA) emphasizes equitable and sustainable use of water resources, this has not been achieved in many rural areas. Over the past few years, it has become quite clear that in large parts of South Africa, and particularly in rural areas, people experience acute water shortages. Reticulated water supply from storage reservoir systems is not common and less capital-intensive set-ups, including boreholes, run-of-river (ROR) supply and rainwater harvesting $(\mathrm{RWH})$, serve as the main sources of water (Ndiritu et al., 2011a). In rural areas of the country, unregulated ROR abstractions are common. Run-of-river abstraction is the direct water abstraction from a river without a storage facility.

While comprehensive yield-reliability analysis for large water resource systems with storage dams is now the norm, typical rural water supply analysis unrealistically aggregates data into monthly or annual time steps and does not incorporate reliability (Ndiritu et al., 2011a). Mallory (2005) noted that models used in SA such as 'water resources yield' and 'water resources planning' models have been successfully used to implement water restrictions/operating rules for systems dominated by storage dams, but little attention has been given to ROR schemes. Examples of such systems include the Orange River system (Mare et al., 2007), Vaal River system (Swart et al., 2007) and Polokwane Water Supply system (Nyabeze et al., 2007). The lack of yield-reliability analysis and operating rules for rural water supply systems characterized by ROR abstractions is disheartening considering that the development of operating rules has advanced to even cater for environmental flow requirements (EFRs) (for example, Hughes et al., 1997; Hughes and Ziervogel, 1998).

\footnotetext{
* To whom all correspondence should be addressed.

e-mail: john.odiyo@univen.ac.za

Received 6 May 2014; accepted in revised form 16 March 2015
}

Mare et al. (2007) performed yield-reliability analysis for Luvuvhu River system but excluded ROR abstractions from Dzindi and Dzingahe systems. Mallory (2002) estimated ROR yield for irrigation supply in the Usuthu Mhlathuze Water Management Area as the lowest flow on record, averaged over 3 months. The latter study acknowledged that the estimated ROR yield is conservative since it assumes that the water demand is constant throughout the year. Hughes (2006) developed a simple model that simulates water balances in small- to medium-sized water resource systems (without major storage), and compared the results with the standard available information on the ecological Reserve. The model was based on the use of monthly flow duration curves (FDCs) to derive operating rules at different levels of assurance of supply for streamflow reduction activities (afforestation), the effects of distributed farm dams and associated abstractions and ROR abstractions throughout a river basin. Hughes (2006) noted the limitations of the approach due to uncertainties resulting from the use of the monthly time step, amongst other sources. IWR (2009) reported that uncertainty in the methods used to estimate baseflows from monthly flow time series data used in the approach developed by Hughes (2006) was a limiting factor.

This brief review reveals the gap and need to undertake yield-reliability analysis and to develop associated operating rules for ROR for rural water supply schemes. The concept of FDCs has been used in this study to derive operating rules for ROR abstractions for domestic water use at a daily time scale. This is considered to be an appropriate and pragmatic approach for scheduling domestic water abstractions since there is no facility to store water for a long period. Hughes (2006) also recognized the limitation of using monthly flow time series data to derive operating rules and proposed the need to disaggregate the monthly data to daily time series data before deriving FDCs for each month. The current study therefore focuses on yieldreliability analysis at a daily scale and the derivation of associated operating rules. 


\section{CASE STUDY AREA}

Siloam Village falls under the quaternary catchment A80A of the Nzhelele River Catchment which is located in the Limpopo Province of South Africa. The study area is found between $22^{\circ} 53^{\prime} 15.8^{\prime \prime} \mathrm{S}$ and $22^{\circ} 54^{\prime} 5^{\prime \prime} \mathrm{S}$ and between $30^{\circ} 11^{\prime} 10.2^{\prime \prime} \mathrm{E}$ and $30^{\circ} 11^{\prime 2} 23.5^{\prime \prime}$ E (Fig. 1).

The major river around the study area is Nzhelele River. The flow pattern of Nzhelele River is highly variable because of low and unpredictable rainfall averaging $350-400 \mathrm{~mm} \cdot \mathrm{a}^{-1}$ (Ashton et al., 2001). During dry years the river is without water for several months. Summer rainfall causes a dramatic increase in flows, though tributary streams are mostly episodic, only containing water after rainfall (Ashton et al., 2001). The mean annual runoff of the quaternary catchment is $160 \mathrm{~mm}$ while the mean annual evaporation varies from 1300-1 $400 \mathrm{~mm}$. The case study area is dominated by human settlements and subsistence agriculture (Fig. 2).

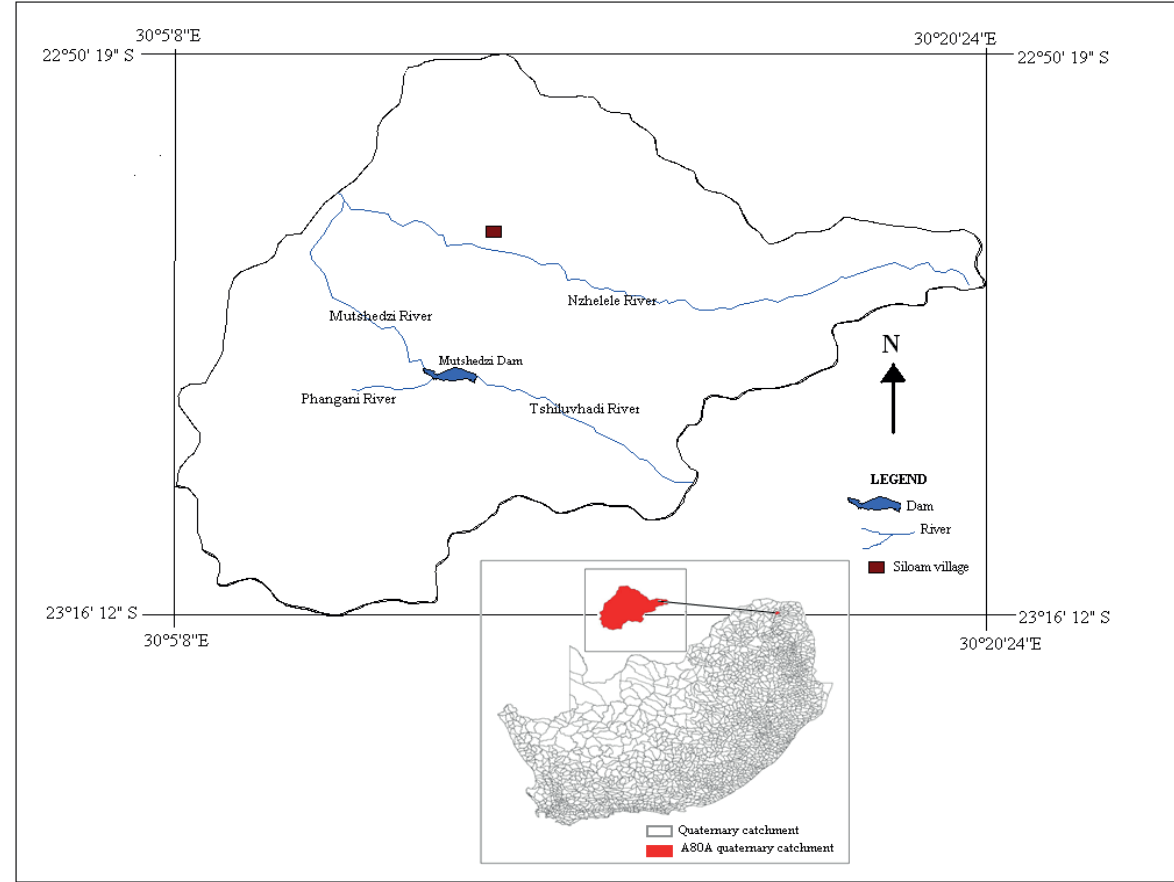

Figure 1

Location of Siloam Village in A80A quaternary catchment

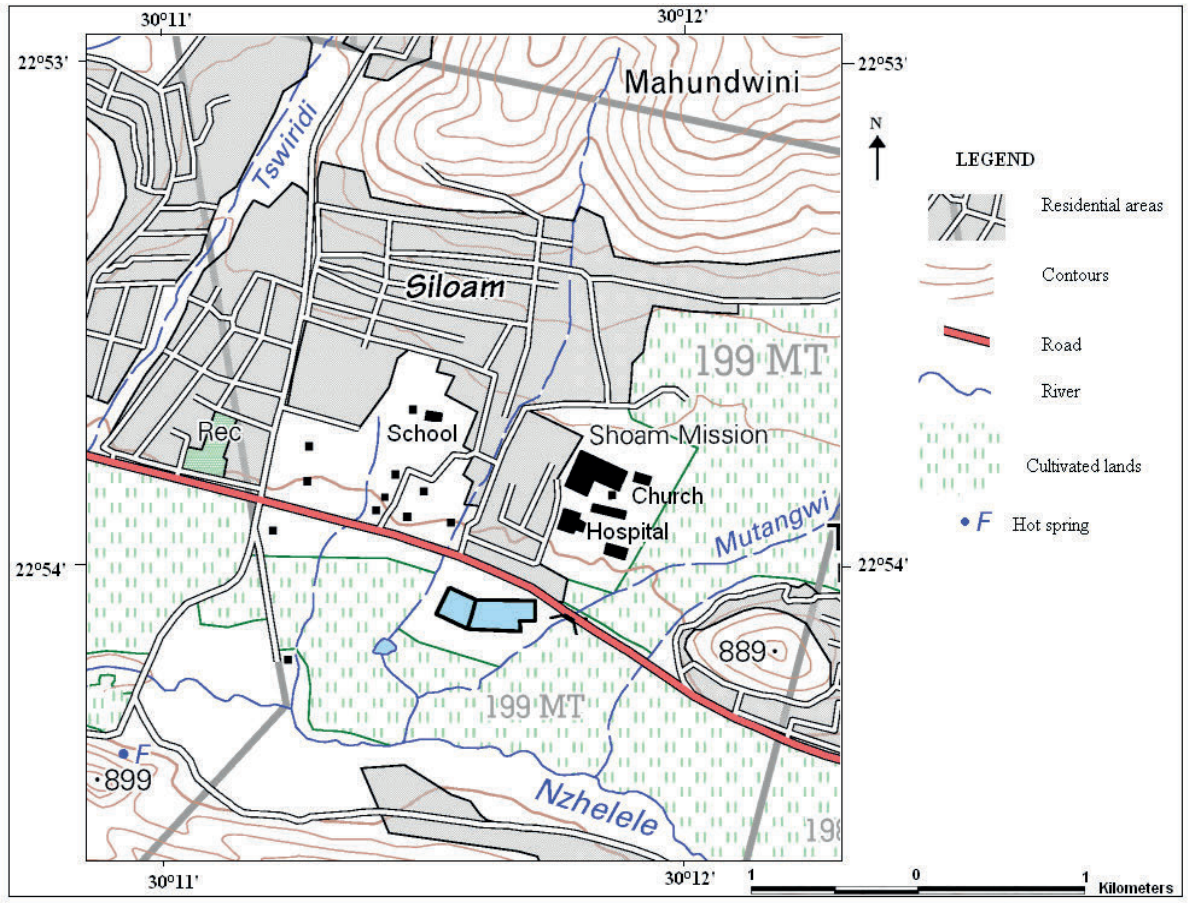

Figure 2

Topographical map for Siloam Village 


\section{METHODOLOGY}

\section{Yield-reliability analysis and derivation of operating rules}

Since Nzhelele River at Siloam Village is unregulated with no storage system (dam/reservoir), FDCs have been used for yield analysis using different percentages of time that the discharge is equalled or exceeded (probability of exceedances). Daily runoff data for the period 1950/01/01-2000/07/31, simulated using the Mike 11 NAM rainfall-runoff model by Makungo (2009), have been used to construct 366 one-day FDCs. A oneday FDC is a flow duration curve constructed from long-term daily runoff data for each day of the year. The generated daily runoff for a period of 51 years were arranged such that the discharges for each date of the year (i.e. 1 Jan 1950, 1 Jan 1951, ..., 1 Jan 2000) were grouped together to form one data set, resulting in 366 data sets, each having 51 runoff data points. This, together with the computation of the percentage of time each discharge was equalled or exceeded, was accomplished with a computer program coded in Fortran. The basis for choosing to use the Mike 11 NAM rainfall-runoff model, and its set-up, calibration and verification, have been discussed in Makungo et al. (2010).

The one-day FDCs for river flow were used to derive daily yields equalled or exceeded at different levels of flow assurances (probability of exceedances). The percentage of time that a particular discharge/yield is equalled or exceeded is the assurance of supply of that particular discharge/yield event (Hughes, 1999, 2001). The low-flow requirement (LFR) component of EFRs was estimated using the procedure described in Smakhtin et al. (2004). EFRs are comprised of LFRs and high-flow requirements (HFRs). According to this method, LFR is considered as the discharge which is exceeded $90 \%$ of the time $\left(\mathrm{Q}_{90}\right)$. This was adopted as an estimate of LFR because Nzhelele River is dominated by low flows, which depict dry/ drought conditions. LFR has been used to set minimum flow requirements for rivers in SA (Tharme, 2003). Scheduling water to meet the LFR component of EFRs maintains the river at a fair state which is considered acceptable from a management perspective (Smakhtin et al., 2004). LFR maintains the aquatic ecosystem and provides water for downstream users. For a ROR scheme, there is typically little impediment to the natural high flows that occur during/after heavy rainfall events. Since HFRs are meant to produce flows that occasionally flush out the system, as would occur in the natural state, this is still expected to happen for a ROR scheme that has no substantial storage and therefore has no ability to hold up the flood events. Thus, HFRs are accounted for naturally.

Run-of-river abstraction operating rules were derived based on the results of water availability assessments and the need to supply LFR and domestic water demand at equivalent supply and reliability levels. The reliability levels that can be achieved by the operating rule were obtained. The operating rules have been derived for daily scheduling of water, taking into account the LFR. In developing the operating rules, LFR and domestic water requirements were considered to be of equal priority, as required by the Department of Water and Sanitation; hence these users should have equal access to available water based on their requirements. The operating rule curves for Siloam Village were derived based on the following equations:

$$
\text { If } Q_{T(t)} \geq D+L F R_{(t)} \text { then, } D S_{(t)}=D
$$

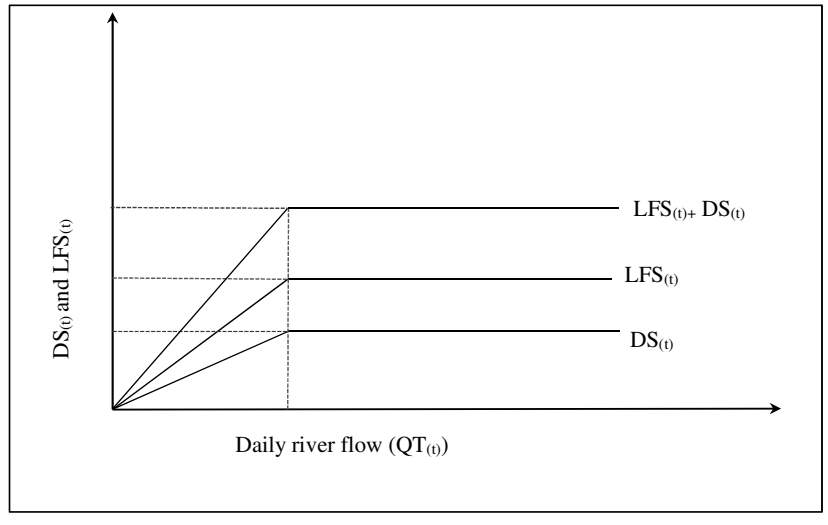

Figure 3

Form of the proposed operating rule curves

$$
\begin{aligned}
& \text { If } Q_{T(t)}<D+L F R_{(t)} \text { then allocate water as follows: } \\
& D S_{(t)}=\frac{D}{D+L F R_{(t)}} Q_{T(t)} \\
& L F R_{(t)}=\frac{L F R_{(t)}}{D+L F R_{(t)}} Q_{T(t)}
\end{aligned}
$$

where: $Q_{T(t)}$ is the measured flow on Day $t, D$ is the specified daily domestic demand, $D S_{(t)}$ is the actual supply for domestic use on Day $t$ and $L F S_{(t)}$ is the actual supply to the environmental flow on Day $t$. Eqs 1 to 3 can be presented graphically as operating rule curves as shown in Fig. 3.

The procedure followed in developing the operating rules for Nzhelele River at Siloam Village has been used as the basis for developing the procedure for deriving generic operating rules that can be applied to any river system in which ROR abstractions are used to fully or partially supply the community with water.

\section{RESULTS AND DISCUSSION}

\section{Yield-reliability analysis}

The one-day FDCs for selected days that represent the wet and dry seasons of the year have been presented to show examples of the daily flow behaviour in Nzhelele River at Siloam Village (Fig. 4). The FDCs have been plotted on a log-linear scale to obtain a clear view, especially during periods of low flows. The FDCs show the amount of water (yield) that is available at different probabilities of exceedances (levels of assurance) for each day of the year. The FDCs also indicate the highly variable nature of Nzhelele River. The daily yield-reliability curves (Fig. 5) from the generated FDCs show the variation of water availability at given LAS on each day of the year. This shows that higher yields are available but at lower LAS. Otherwise, yields are generally lower at high LAS. The gaps from Days 24 to 35,304 to 341 and 344 to 363 show periods of zero flows in the river at $98 \%$ LAS, which cannot be represented at log scale. In Fig. 5, Day 1 is 1 January and Day 366 is 31 December, considering a leap year.

\section{Water requirements for domestic use and LFR}

Water requirements (target draft) for domestic use for Siloam Village shown in Table 1 are based on the information from the Department of Water Affairs and Forestry (DWAF) Limpopo 

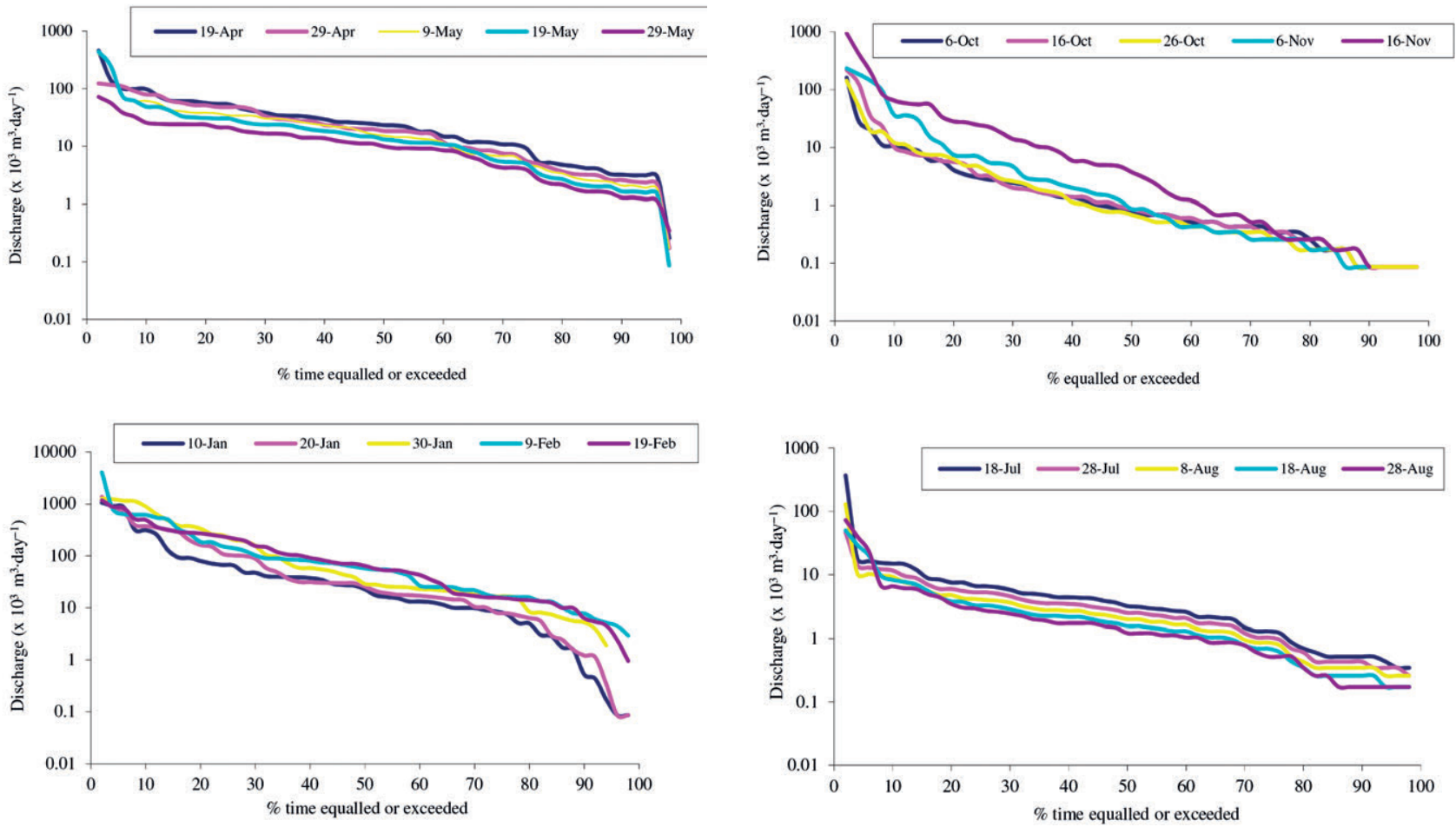

Figure 4

One-day FDCs for Nzhelele River at Siloam Village (from Mike 11 NAM simulated runoff)

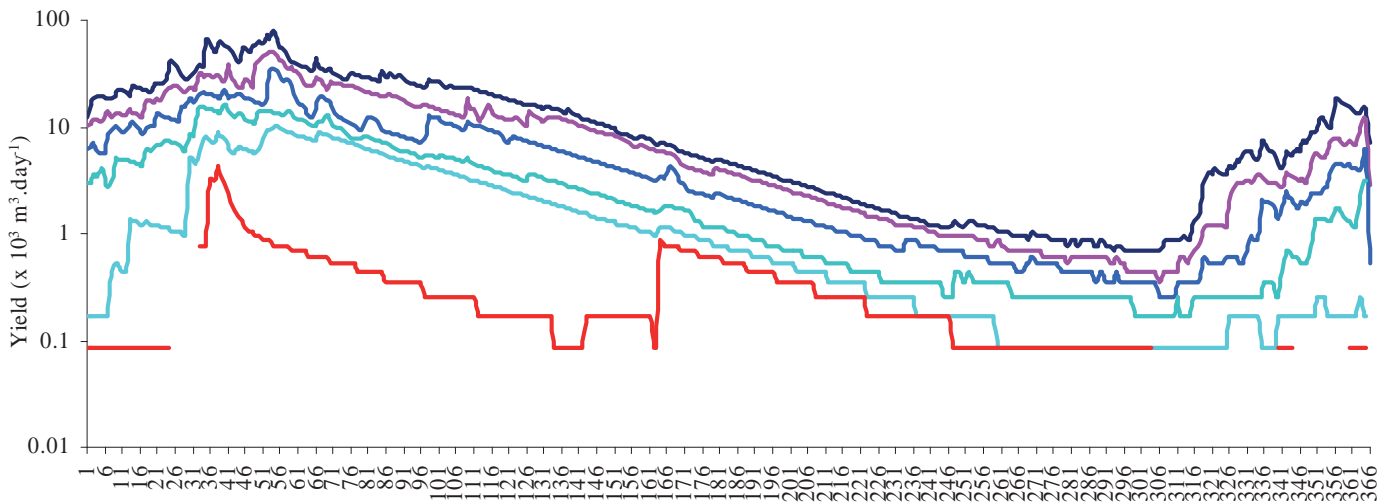

Da

$-50 \%$ LAS $— 60 \%$ LAS — $-70 \%$ LAS — $-80 \%$ LAS — $-90 \%$ LAS $-98 \%$ LAS

Figure 5

Daily yield curves at different levels of assurance of supply

Table 1

Domestic water requirements*

\begin{tabular}{|l|c|c|}
\hline Level of supply service & Water requirement $\left(\boldsymbol{\ell} \cdot\right.$ capita.day $\left.^{-1}\right)$ & $\begin{array}{c}\text { Target draft for a population of } \mathbf{2} \mathbf{1 6 8} \\
\left(\mathbf{m}^{\mathbf{3}} \cdot \mathbf{d a y}^{-\mathbf{1}} \mathbf{)}\right.\end{array}$ \\
\hline Low & 15 & 34.69 \\
\hline Medium & 25 & 54.20 \\
\hline High & 35 & 75.88 \\
\hline
\end{tabular}

* DWAF Limpopo Water Services (DLWS, 2008) 
Water Services (DLWS, 2008) on per capita requirements at low, medium and high levels of supply services, and on a projected population size of 2168 for Siloam Village in the year 2012. At a low level of supply service, water allocated is only adequate for domestic uses such as drinking and cooking, while at the medium level of supply service water allocated is only adequate for domestic uses such as drinking, cooking and washing. At a high level of supply service the allocated supply can be used for other activities within the homestead such as home gardening. The use of 3 different levels of supply services, which are 'low', 'medium' and 'high' (Table 1), allows for the allocation of water depending on the available yield in the river at a certain time. This enables allocation of more water to domestic users during times of high flows. The daily LFRs for Nzhelele River at Siloam Village, based on the proposal by Smaktin et al. (2004), are shown in Fig. 6.

\section{Reconciliation of water availability with requirements}

Figure 7 shows the reconciliation of water availability with domestic water requirements for low (DL), medium (DM) and high (DH) levels of supply services, as well as the LFR and the total water requirements (TWR). TWR1, TWR2 and TWR3 represent the total water requirements for DL and LFR, DM and LFR, and DH and LFR, respectively. Figure 7 shows that the TWR can be met at approximately $90 \%(1: 10)$ LAS for DL and DM, provided that the total yield is equally allocated to LFR and domestic users. However, TWR can be met at all levels of supply services at 50-80\% LAS since relatively higher yields are available at these LAS. This shows that the domestic water requirements can only be met at a high level of supply service at relatively low LAS compared to the recommended LAS by DWAF (2004) for domestic use. DWAF (2004) indicated that $10 \%$ of the basic human needs should be met at $99.5 \%(1: 200)$ LAS, as a requirement of the National Water Act, and that the rest can be met at $99 \%$ (1:100), 98\% (1:50) and 95\% (1:20), depending on the amount of water available in the system.

The results show that the water available in Nzhelele River at Siloam Village cannot meet the LFR as recommended by Mallory (2005), and domestic water requirements at the three levels of supply services as recommended by DWAF (2004) and Mallory (2005). Thus, if the domestic water requirements are

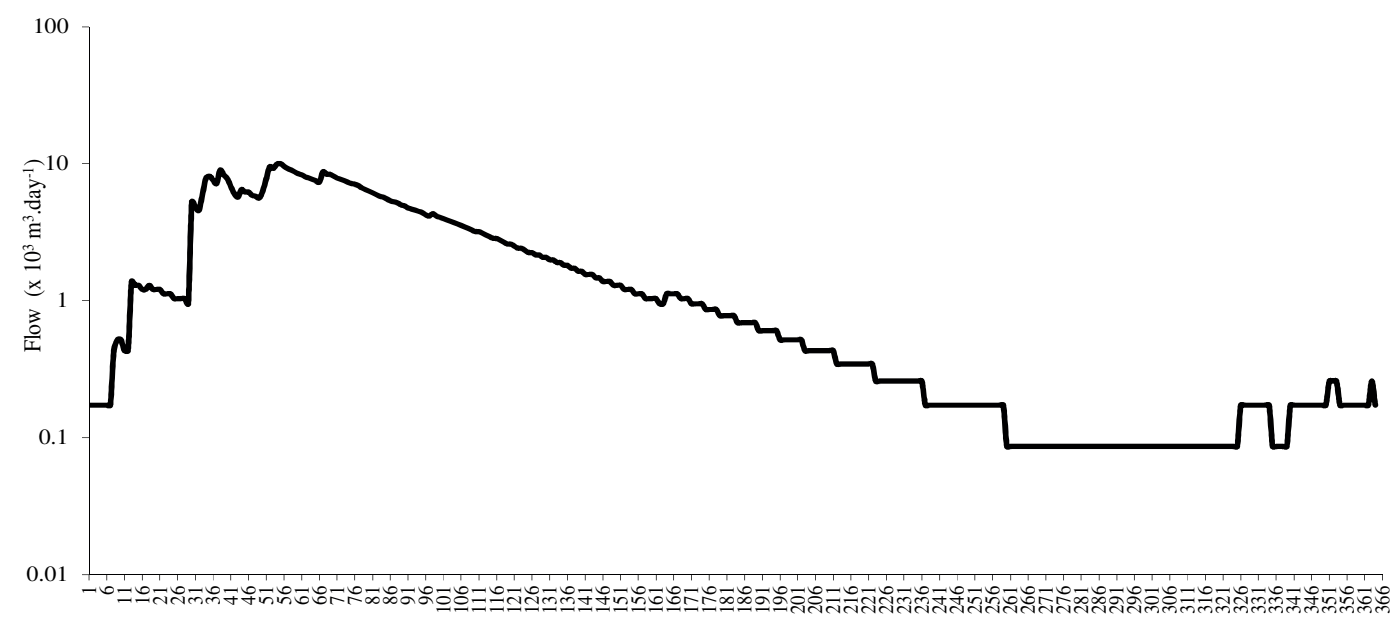

Day

Figure 6

LFR for Nzhelele River at Siloam Village

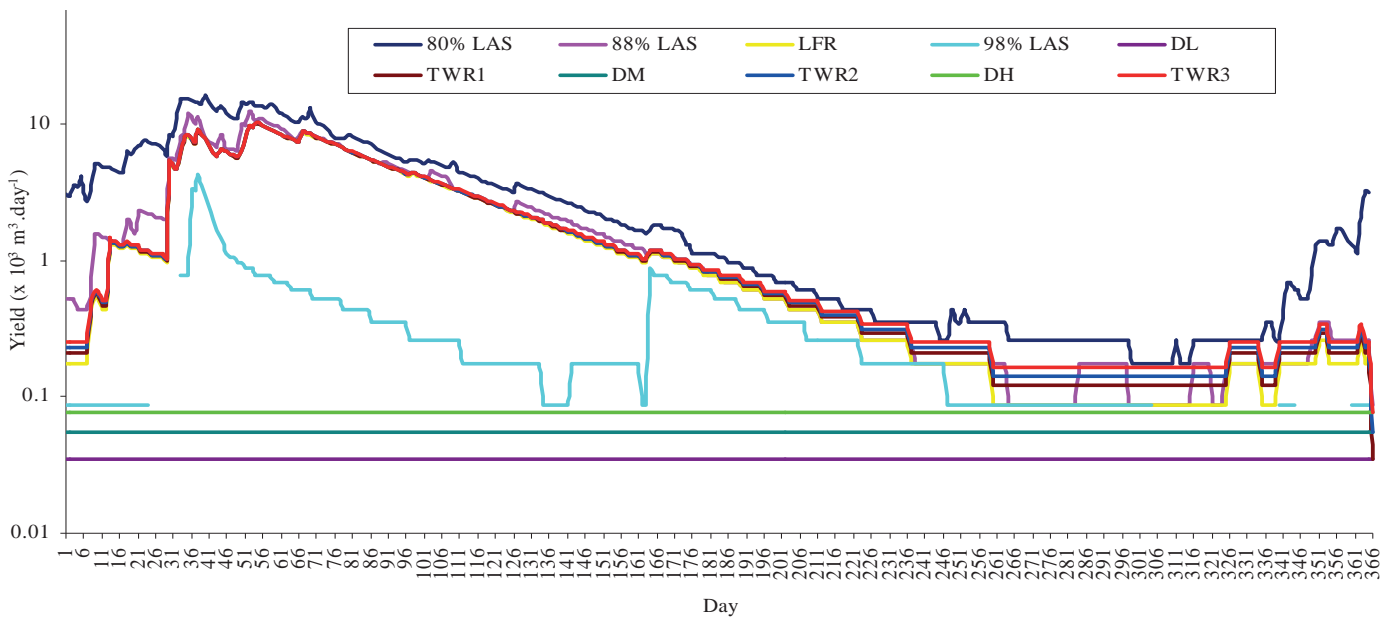

Figure 7

Yield compared with domestic water supply at DL, DM and DH levels, LFR and TWR 
to be met at these LAS, then other sources of supply would be required to supplement the ROR supply. For example, Ndiritu et al. (2011a, b) showed that integration of RWH and ROR supply improves yield and reliability up to $96 \%$ (1:25) for a period of 9 months. This underscores the need to integrate all of the available sources of water to supply the water requirements in water-scarce rural areas at the recommended LAS.
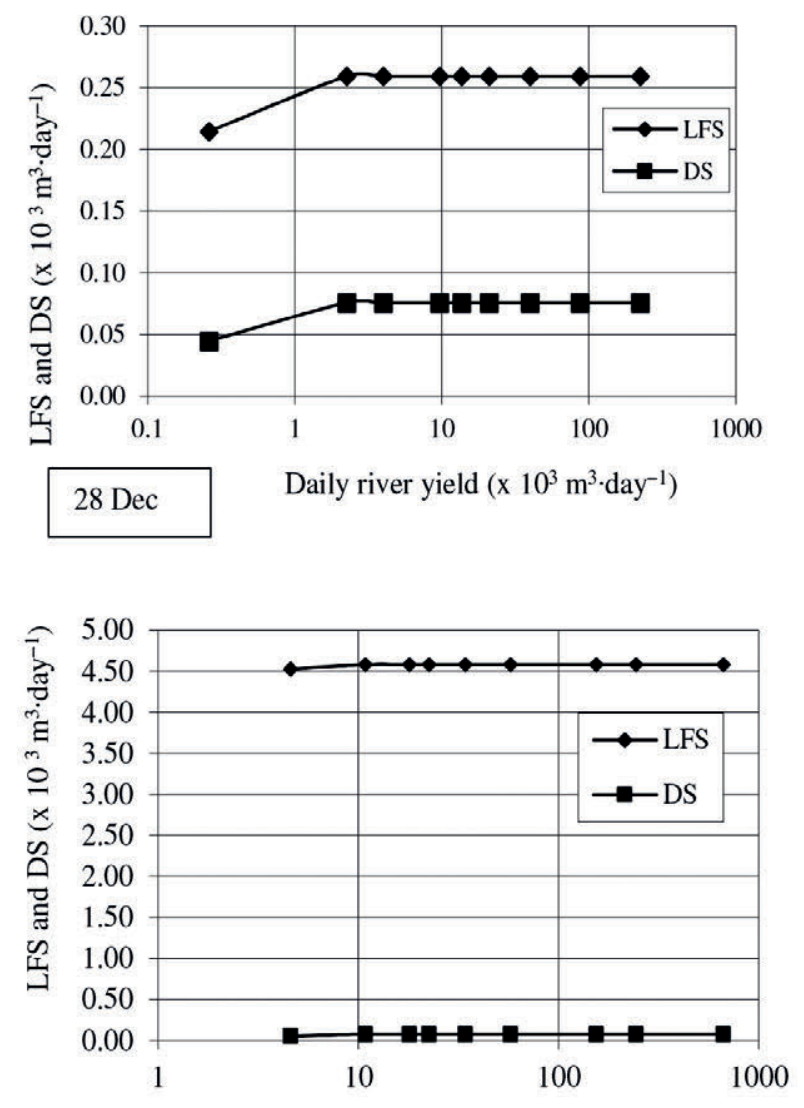

\section{$01 \mathrm{Feb}$}

Daily river yield $\left(\times 10^{3} \mathrm{~m}^{3} \cdot \mathrm{day}^{-1}\right)$

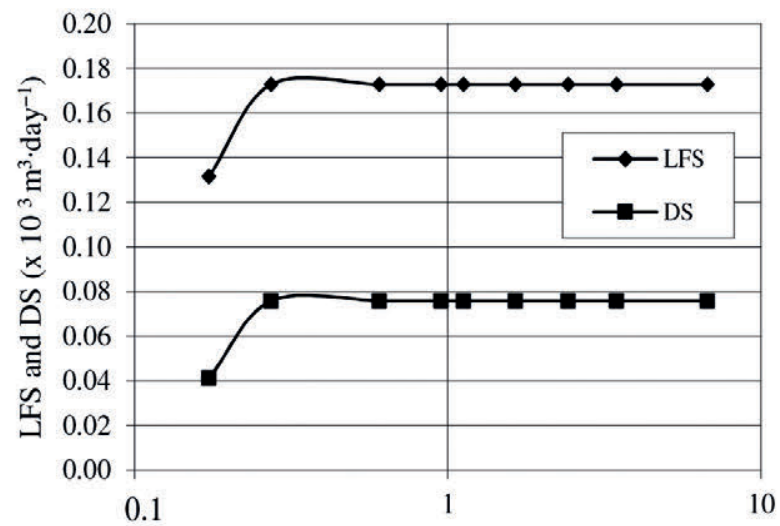

28 Aug Daily river yield $\left(\times 10^{3} \mathrm{~m}^{3} \cdot\right.$ day $\left.^{-1}\right)$

\section{Operating rules}

Figure 8 shows examples of operating rule curves for selected days that represent the wet and dry seasons of the year. The operating rule curves have been plotted on a log-linear scale for easier interpretation of the results. The operating rule curves show the volume of water that can be supplied to domestic

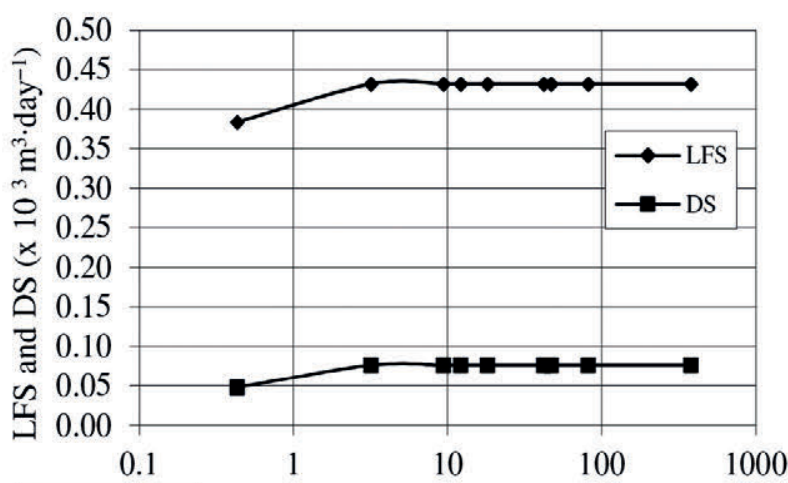

08 Jan Daily river yield $\left(\times 10^{3} \mathrm{~m}^{3} \cdot\right.$ day $\left.^{-1}\right)$

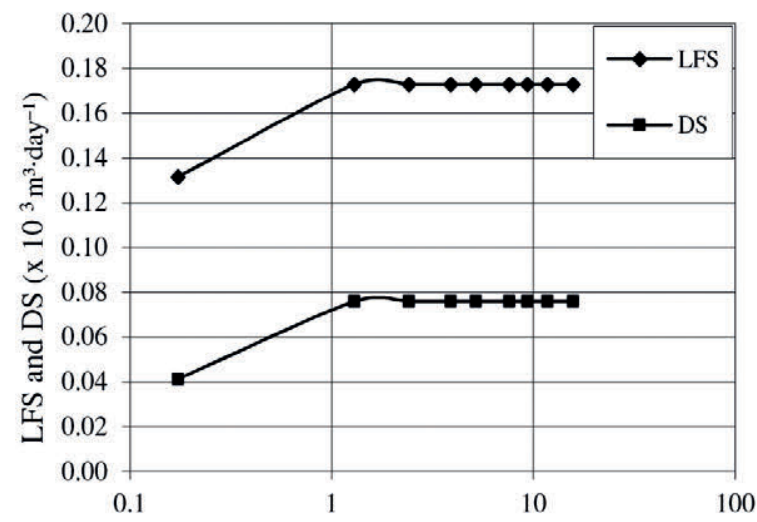

24 June Daily river yield $\left(\mathrm{x}_{10} 0^{3} \mathrm{~m}^{3} \cdot \mathrm{day}^{-1}\right)$

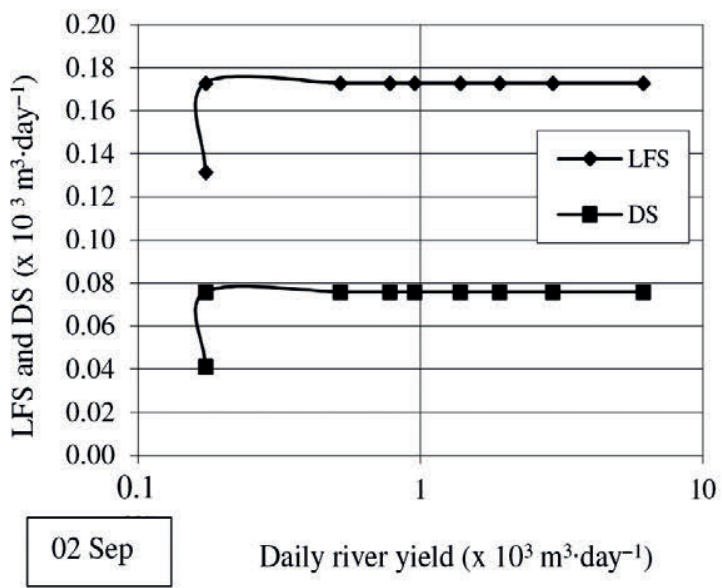

Figure 8

Examples of operating rule curves 
users and the environment on a particular day. The generation of the curves can be automated on a daily basis or Eqs 1 to 3 can be programmed so that the supplies for a given day are obtained instantly once the daily flow $\mathrm{QT}_{(\mathrm{t})}$ has been measured and input. Interpretation of Fig. 8 is as follows:

(i) At river yields less than $2.25 \times 10^{3}, 2.76 \times 10^{3}$ and $10.8 \times$ $10^{3} \mathrm{~m}^{3}$.day ${ }^{-1}$ for 28 December, 8 January and 1 February, respectively, the DS and LFS are allocated water according to Eqs 2 and 3.

(ii) At river yields less than $1.30 \times 10^{3}, 0.27 \times 10^{3}$ and $0.17 \times 10^{3}$ $\mathrm{m}^{3}$. day ${ }^{-1}$ for 24 June, 26 August and 2 September, respectively, the DS and LFS are allocated water according to Eqs 2 and 3.

(iii) At river yields higher than those specified in (i) and (ii) for the same dates, DS and LFS are allocated water according to Eq. 1.

For (i) and (ii), DS is supplied at a DM level of supply service or in extreme drought conditions at a DL level of supply service, as the river water can only partially meet the DS and LFS. For (iii), DS is supplied at a DH level of supply service as the river water can fully meet the DS and LFS.

\section{The procedure for deriving generic operating rules for ROR abstractions}

The procedures followed in developing the operating rules for Nzhelele River at Siloam Village have been summarized to provide the generic operating strategy that can be applied to any river system in which ROR abstractions are used to fully or partially supply the community with water. The procedure is as follows:

1. Determine the existing water uses and their requirements including the daily LFR.

2. Obtain or simulate daily streamflow and develop 1 day FDCs.

3. Derive yield curves from one-day FDCs by extracting the discharges that have been equalled or exceeded at specific percentage times/levels of assurance of supply.

4. Superimpose the daily water requirements for the year on the derived yield curves.

5. Determine the LAS which meets the water requirements.

6. Measure the flow at the point of interest (assumes the required infrastructure is available).

7. Allocate water following Eqs 1 to 3.

\section{CONCLUSIONS}

The study conducted yield-reliability analyses and derived operating rules for ROR abstractions using Siloam Village as a case study. The findings of the study indicate that Nzhelele River water can meet the domestic water requirements at low, medium and high levels of supply and LFR at $50-80 \%(1: 2-1: 5)$ LAS. The low-flow and basic domestic water requirements can be partially met at $90 \%(1: 10)$ LAS. As the domestic water requirements cannot be supplied at the recommended LAS of $99 \%$ (1:100), 98\% (1:50) and 95\% (1:20), additional sources of supply need to be considered to help to achieve these reliability levels. Ndiritu et al. (2011a, b) showed that integration of sources improves the reliability of supply. A study that involves the development of an integrated water supply scheme involving ROR abstractions and the other sources such as groundwater and rainwater is recommended. This will improve on the LAS at which the total water requirements are met throughout the year.
The study presented examples of operating rule curves for the study area. To facilitate efficient implementation of the derived operating rules for Nzhelele River at Siloam Village, infrastructure such as an abstraction weir, transfer pipes and a reservoir (tank) may need to be provided. The procedure used in developing the operating rules for Nzhelele River at Siloam Village has been summarized to provide the generic operating rules that can be applied to any river system in which ROR abstractions are used to fully or partially supply the community with water.

\section{ACKNOWLEDGEMENTS}

The authors wish to acknowledge the funding obtained for part of the study from the Sub-Directorate of Systems Operations of Department of Water Affairs under the Bulk Water Supply Systems Operation: Evaluation and Monitoring Support project.

\section{REFERENCES}

ASHTON P, LOVE D, MAHACHI H and DIRKS P (2001) An overview of the impacts of mining and mineral processing operations on water resources and water quality in the Zambezi, Limpopo and Olifants catchments in Southern Africa. MMSD Southern Africa Research Reports, Report No. ENV-P-C 2001-042, CSIR Environmentek, Pretoria, South Africa and Geology Department, University of Zimbabwe, Harare, Zimbabwe.

DLWS (2008) Bulk infrastructure feasibility planning, Project LPR00@ Nzhelele RWS, $2^{\text {nd }}$ draft. Vhembe District Municipality, Limpopo Province.

DWAF (DEPARTMENT OF WATER AFFAIRS AND FORESTRY, SOUTH AFRICA) (2004) Urgent need for augmentation of the Mgeni system. DWAF, Pretoria.

HUGHES DA (1999) Towards the incorporation of magnitudefrequency concepts into the building block methodology used for quantifying ecological flow requirements of South African rivers. Water SA 25 (3) 279-284.

HUGHES DA (2001) Providing hydrological information and data analysis tools for the determination of ecological instream flow requirements for South African rivers. J. Hydrol. 241 140-151.

HUGHES DA (2006) A simple model for assessing utilizable streamflow allocations in the context of the ecological Reserve. Water $S A$ 32 (3) 411-417.

HUGHES DA, O’KEEFFE JH, SMAKHTIN V and KING JM (1997) Development of an operating rule model to simulate time series of reservoir releases for instream flow requirements. Water $S A 23$ (1) 21-30.

HUGHES DA and ZIERVOGEL G (1998) The inclusion of operating rules in a daily reservoir simulation model to determine ecological reserve releases for river maintenance. Water SA 24 (4) 293-302.

IWR (INSTITUTE FOR WATER RESEARCH) (2009) Identification, estimation, quantification and incorporation of risk and uncertainty in water resources management tools in South Africa, Deliverable no. 6: Initial report on systems model uncertainties. Water Research Commission Project No: K5/1838. URL: http:// www.ru.ac.za/static/institutes/iwr/uncertainty/k51838/DEL6 systems_model_uncertainty.pdf (Accessed 6 June 2012).

MAKUNGO R (2009) An operating strategy for run-of-river abstractions for typical rural water supply schemes using Siloam Village as a case study. Masters dissertation, University of Venda.

MAKUNGO R, ODIYO JO, NDIRITU JG and MWAKA B (2010). Rainfall runoff modelling approach for ungauged catchments: a case study of Nzhelele River Sub-Quaternary Catchment. Phys. Chem. Earth 35 596-607.

MALLORY SJL (2002) Overview of the water resources of the UsutuMhlathuze Water Management Area. DWAF/DFID Strategic Environmental Assessment Report. Department of Water Affairs and Forestry, Pretoria. 
MALLORY SJL (2005) The modelling of water restriction applied in complex bulk water supply systems and the application of these techniques to operationalising the ecological Reserve. In: Proceedings of the $12^{\text {th }}$ South African National Hydrology Symposium, 5-7 September 2005, Pretoria.

MARÉ HG, MWAKA B and SINHA P (2007) Development of simplified drought operating rules. URL: http://www.miya-water.com/ data-and-research/articles-by-miyas-experts/water-resource-management (Accessed 1 April 2012).

NDIRITU JG, ODIYO JO, MAKUNGO R, NTULI C and MWAKA B (2011a) Yield-reliability analysis for rural domestic water supply from combined rainwater harvesting and run-of-river abstraction. Hydrol. Sci. J. 56 (2) 238-248.

NDIRITU JG, ODIYO JO, MAKUNGO R, NTULI C and MWAKA B (2011b) Incorporating hydrological reliability in rural rainwater harvesting and run-of-river supply. In: Bloschl G, Takeuchi K, Jain
SK, Farnleitner A and Schumann AH (eds) Risk in Water Resources Management. IAHS Publication no 347. IAHS, Melbourne.

NYABEZE WR, MALLORY S, HALLOWES J, MWAKA B and SINHA $P$ (2007) Determining operating rules for the Letaba river system in South Africa using three models. Phys. Chem. Earth 32 1040-1049.

SMAKHTIN VU, DÖLL P and REVENGA C (2004) A pilot global assessment of environmental water requirements and scarcity. Water Int. J. 29 (3) 307-317.

SWART HS, VAN ROOYEN PG, MWAKA B and NTULI C (2007) Operating rules for dams with high evaporation losses. URL: http://www.miya-water.com/data-and-research/articles-by-miyasexperts/water-resource-management (Accessed 3 May 2012).

THARME RE (2003) A global perspective on environmental flow assessment: emerging trends in the development and application of environmental flow methodologies for rivers. River Res. Appl. J. $191-45$. 